\title{
Power quality mitigation and transient analysis in AC/DC hybrid microgrid for electric vehicle charging
}

\author{
Sumana Sreenivasa Rao, Dhanalakshmi Rangaswamy \\ Department of Electrical and Electronics Engineering, Dayananda Sagar College of Engineering, Bengaluru, India
}

\begin{tabular}{l}
\hline \hline Article Info \\
\hline Article history: \\
Received Jul 15, 2021 \\
Revised Oct 26, 2021 \\
Accepted Nov 1, 2021 \\
\hline
\end{tabular}

\section{Keywords:}

Dynamic load model

EV model

Harmonics

Hybrid micro grid

UPQC

\begin{abstract}
The usage of electric vehicles (EV) increased in recent years as the vehicles design and performances are nearly similar to petrol vehicles. The main source of energy for EV is taken from the grid for charging. So, the penetration of EVs in alternating current (AC) grid creates more power quality issues like voltage sag, swell and harmonics in the current. This energy can also be produced from the renewable energy resources like photovoltaic (PV) power generation. This PV energy can also be used as direct current (DC) grid. The electric vehicle chargers which come with intelligent grid operation is considered as load in this paper. This paper is an attempt to discuss the penetration of EVs in AC/DC hybrid micro grid which causes the power quality problems, and the power quality problem is mitigated by using the unified power quality conditioner (UPQC). The results are analyzed for three cases and four scenarios which is based on the function of UPQC and the action of smart charger in grid connected as well as autonomous mode operation of the AC/DC micro grid when the load is considered as dynamic load. The simulation is carried out in MATLAB2017b environment.
\end{abstract}

This is an open access article under the CC BY-SA license.

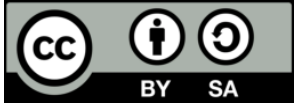

\section{Corresponding Author:}

Sumana Sreenivasa Rao

Department of Electrical and Computer Engineering

Dayananda Sagar College of Engineering

Shavige Malleswara Hills, Kumaraswamy Layout, Bengaluru-560061, India

Email: sumana-eee@dayanandasagar.edu

\section{INTRODUCTION}

The unified power quality conditioner (UPQC) is which works like both series dynamic voltage restorer (DVR) and shunt active power filter (SAPF). Compensation is much needed in recent day at the distribution side. As the power quality of the distribution side is affected much by the battery-based devices. These devices are used to charge the batteries for example laptops, mobile phones and Electric vehicles. These devices utilize the fast-charging concept which takes high current from the utility and it produces voltage sag, as well as current harmonics also increases. To tackle these issues many literatures are published.

The optimization incorporation in selective elimination of harmonics [1] with modified topology of UPQC. The selection of size of the UPQC in the power system and location of the same in bigger distribution system is also become important [2]. The modification of converter topology also improves the power quality in some cases [3], [4] like to supply some active power to the power system by using renewable sources and also modification of the reference theory based on artificial intelligence which makes better control on DClink voltage to get rid of the transient [5], [6].

The electric vehicle (EV) is the recent power quality threat if the number of EVs are increased. The impact of EV station if it is connected to the power grid is analyzed in [7], [8]. When the EVs are used then 
there is one option of vehicle to grid (V2G), the battery connected in the EVs used as power source in the utility. The harmonic problems due to the V2G enabled EVs incorporation is analyzed in [9]. The effects of the EVs connected to grid is analyzed in [10]. The V2G EVs uses alternating current/ direct current (AC/DC) converter for charging. These chargers may be affected due to the usage of the intermittent power source like solar and wind to protect that a new control is proposed in [11]. A new topology of bidirectional power transmission for charging and mitigating the power quality by using the sliding mode control is implemented in [12]. The bidirectional operation causes the voltage problems in the grid when using it as V2G and G2V an low voltage ride through (LVRT) is used to improve the voltage profile in [13], [14]. The characteristics of the AC and DC chargers are discussed in [15]. The grid connected mode and islanded mode of power system operation is done using the PV and wind system for charging the EVs are considered in [16]. A modular multilevel converter (MMC) is used in mitigation of power quality while using the EVs are discussed in [17]. The AC/DC hybrid micro grid is structured with the power quality issue mitigation is discussed in [18]-[20]. The power factor improvement in the front end of the EV charger is proposed in [21]. The detailed literature survey on the topologies of EV chargers with comparison of efficiency, cost and power factor is presented in [22] and the proposed smart EV charger voltage drop is mitigated in [23]. The hybrid AC/DC micro grid is modelled and simulated with grid connected and islanded mode by using the UPQC control using different optimization technique in [24], [25]. The solution to voltage fluctuations using distribution static synchronous compensator (D-STATCOM) under different scenarios proposed in [26]. Review on various control strategis on inveters in microgrid for unbalanced and non-linear loads discussed in [27].

In this paper an $\mathrm{AC} / \mathrm{DC}$ hybrid micro grid is presented using the two-level inverter by using the control of Active power filter (APF) and dynamic voltage restorer (DVR). The dynamic voltage restorer works as the voltage maintaining device in islanded mode. APF is used to remove the harmonics in the supply current when the EVs are connected. Here three cases are discussed. In case 1 is without UPQC and with EV smart chargers at the EV/load side. In case 2 the UPQC is incorporated in the system and it work in grid connected mode. In case 3, it works with UPQC and EV smart charger under condition of islanded mode is discussed. The Simulation Implementation is carried out in MATLAB2017b and the results along with conclusion is discussed.

\section{RESEARCH METHOD}

\subsection{Methodology}

Figure 1 shows the block diagram of the proposed system with UPQC and EV smart charger. The control schemes of UPQC comprises of APF and DVR regulators. APF regulator measures the load voltages, capacitor voltage, load currents and inserted currents. The regulator algorithm of APF develops the measured values and produces the needed reimbursement signals. These signals are then equated in hysteresis controller and the required gate signals are generated. DVR controller measures the supply voltages to produce the required reimbursement and sag/swell recognition signals. These signals are then equated in PWM controller and the needed gate signals are produced. The PV system and a battery are used as DC grid. The control strategy change can make the PV and battery power to be used as the islanded mode source of power. The switch ' $\mathrm{S}$ ' in the diagram is used to switch between grid connected mode and islanded mode.

\subsection{AC-DC micro grid}

The test system works in both grid-connected and islanded mode. The UPQC works as the synchronizing inverter to deliver the power to the load from the DC grid. The DC grid is connected with the PV panel which is connected to the boost converter. The boost converter is connected to the backup battery. This setup provides the constant DC link voltage. This voltage is utilized by UPQC for power quality improvement in grid connected mode and inverts this DC voltage to AC in islanded mode. The switch ' $\mathrm{S}$ ' is specified in the block diagram, If $S=1$ then it is connected to the grid and the three phase Phase Locked Loop (PLL) is in action. When the switch ' $\mathrm{S}$ ' is zero it becomes as islanded mode. The islanding enables the virtual PLL.

Figure 2, shows the circuit diagram of the electric vehicle charger used in the electric vehicle. It is connected to the single phase of the three-phase system. The other two phases also carry the same. This circuit is controlled with the constant current mode for fast charging.

The battery charge controller as shown in Figure 3 works like a droop controller. The Nominal current $\left(\mathrm{I}_{\mathrm{nom}}\right)$ and nominal voltage $\left(\mathrm{V}_{\mathrm{nom}}\right)$ are considered here for not exceeding the current rating of the battery and voltage range of grid. Baterry charge controller sends the command current signal to the charger according to the grid voltage sag conditions. 


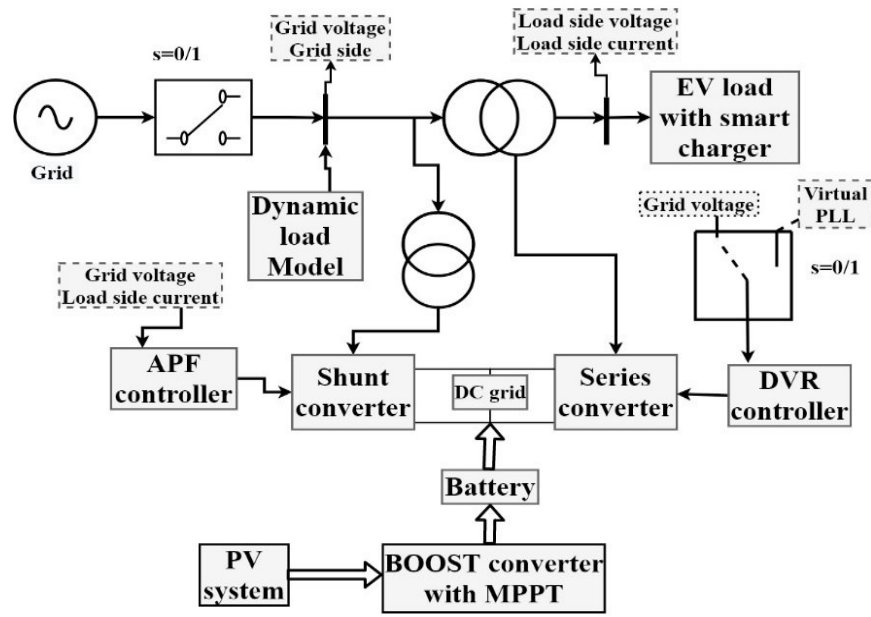

Figure 1. Block diagram of the proposed system

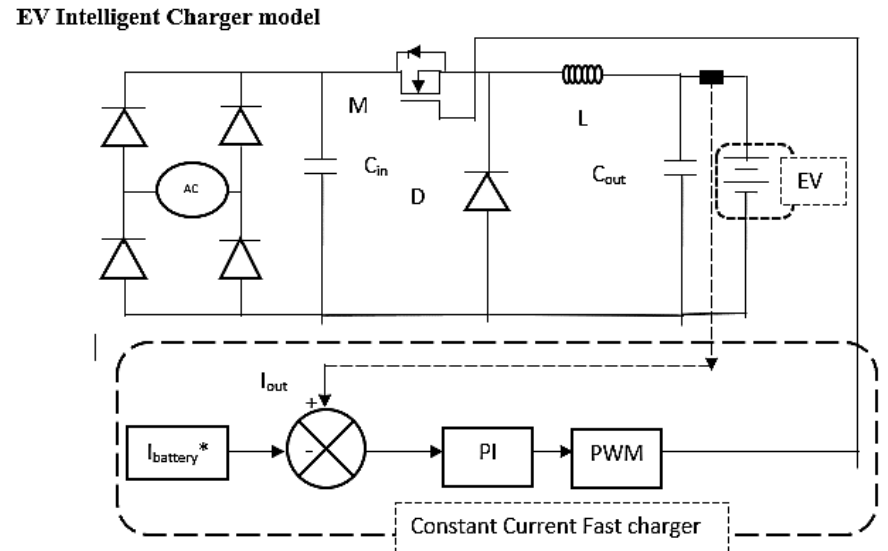

Figure 2. EV intelligent charger model

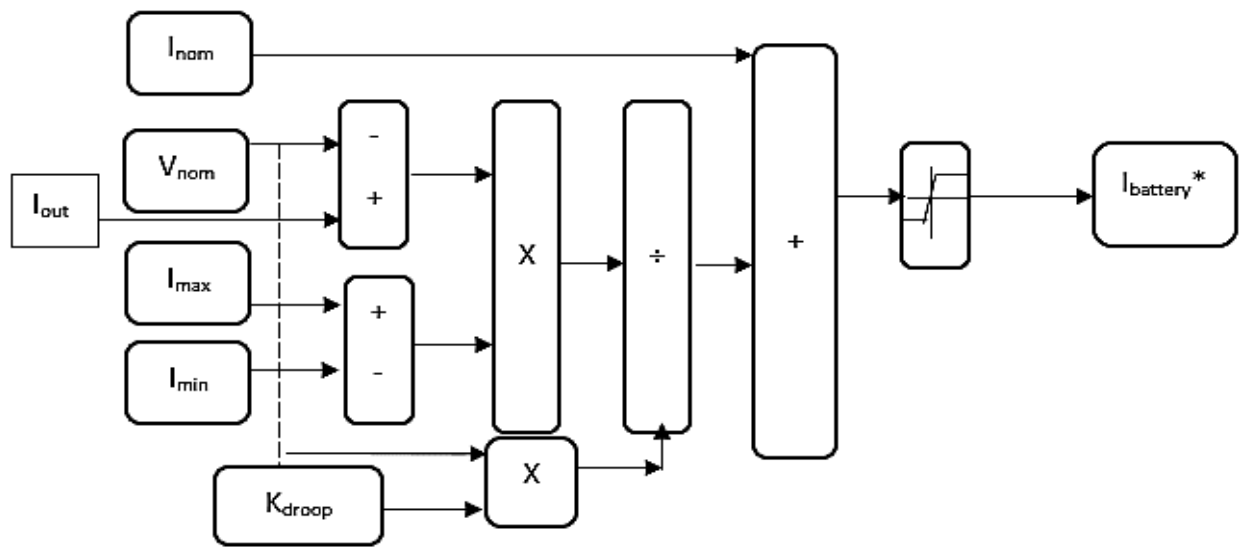

Figure 3. EV intelligent charge controller

\subsection{Load trip model}

The simulation of simple load model of the proposed system is shown in Figure 4, it is made to run for 1 second. Here six loads are taken and each load is switched by $1 / 6^{\text {th }}$ time. At the initial stage, $1 / 6^{\text {th }}$ of 
$45 \mathrm{~kW}$ is connected. Then at the instant of $2 / 6^{\text {th }}$ time, $2 / 6^{\text {th }}$ of the load is connected. This will continue till full load. The simulation is carried out for the parameters given in the Table 1 . The concept is given as the mathematical model.

$$
P_{\text {load }}(i)=\left(\frac{i}{6}\right) * P ; \text { here } i=1 \ldots, 6 ; P \text { is the load power }
$$

\section{Load at grid}

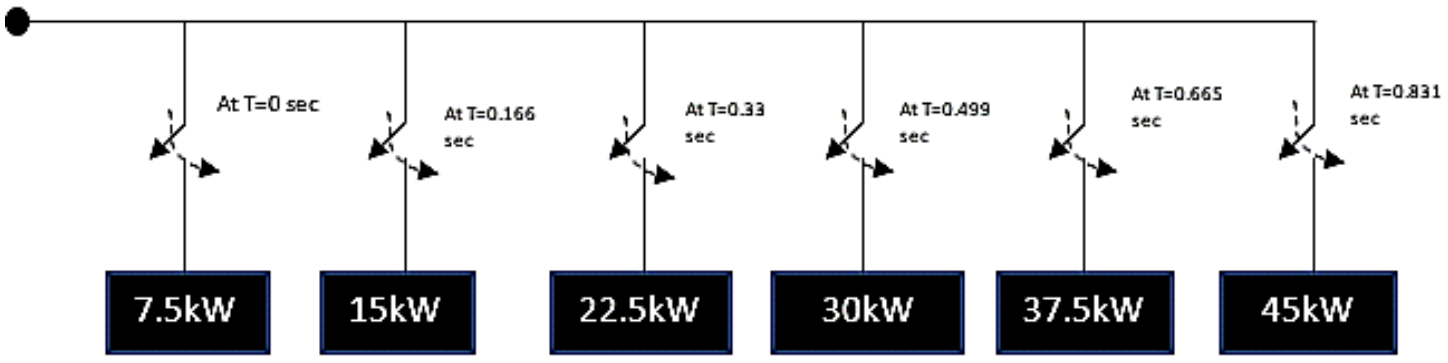

Figure 4. Load trip model

Table 1. Parameters used in the simulation

\begin{tabular}{clc}
\hline Equipment & \multicolumn{1}{c}{ Parameters } & Values \\
\hline PV rating & Voc in V & 37.2 \\
& Vmp in V & 30.2 \\
& Isc in A & 8.62 \\
& Imp in A & 8.1 \\
& number of series connections & 20 \\
& number of parallel connections & 2 \\
Boost converter & Inductor in H & $12 \mathrm{u}$ \\
& Capacitor in F & battery capacitance \\
& Frequency in Hz & $5 \mathrm{k}$ \\
EV battery & Type & Li-on \\
& Nominal voltage in v & 48 \\
& Rated capacity Ah & 400 \\
EV Charger & Inductor in H & $.03 \mathrm{~m}$ \\
& Capacitor in F & $2200 \mathrm{u}$ \\
& Frequency in HZ & $20 \mathrm{~K}$ \\
\hline
\end{tabular}

\section{RESULTS AND DISCUSSION}

This simulation is done for three cases and three scenarios.

- Case 1: without UPQC and with EV smart charger at the EV side/load side. This system runs under grid connected mode.

- Case 2: the circuit connected with UPQC and smart charger and runs under grid connected mode.

- Case 3: in islanded mode, when DC grid is supplying the AC load and also the charger is connected with EVs.

There are three scenarios they are based on the smart charger action.

- Scenario 1: shows the smart charger is in off state.

- Scenario 2: shows the smart charger in action for all the three phases with 6A minimum charging current.

- Scenario 3: works with the smart charger in action at two phases only.

In this simulation, the $\mathrm{AC}$ grid is connected to EVs and dynamic loads. The DC gird is connected at the DC link of the UPQC. The EVs are connected in each of the phases as single-phase smart chargers. The behavior of the smart charger is when the Voltage at the AC grid is not within the safer range then the smart charger reduces its charging current for maintaining the voltage in the $\mathrm{AC}$ grid. This can go till 6A minimum and 16A maximum. If the voltage of $\mathrm{AC}$ grid is within limit it takes maximum current from the grid to charge the EVs. The UPQC is connected between the midpoints of AC grid and loads. This UPQC has the PV power at the DC link as the DC grid which charges the battery to maintain the DC link voltage. This PV power can supply the real power to the AC grid to support the voltage at the AC grid by the UPQC DVR control. The harmonics of the load can also be compensated from the UPQC APF control. The simulation results are given below for different scenarios. 


\subsection{Scenario 1: smart charger in OFF state}

The simulation is carried out for the case 1. Figure 5(a) shows the voltage and Figure 5(b) shows the current waveform under the condition of without UPQC and smart EV chargers. The graph is in RMS value. From the Figure 5(a) it can be absorbed that the dynamic load which are connected with AC grid makes the voltage drop in every $0.1 \mathrm{secs}$ of the simulation run time. When the dynamic load increases the voltage drops as step by step. As there is no connection to the smart charger, the EVs draw the required current from the grid is as shown in Figure 5(c). The corresponding values are tabulated in Table 2.

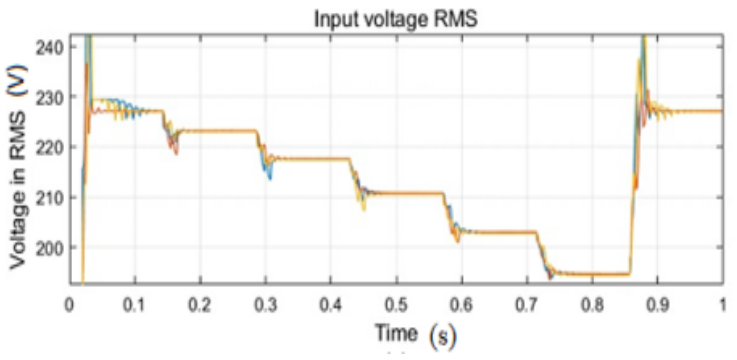

(a)

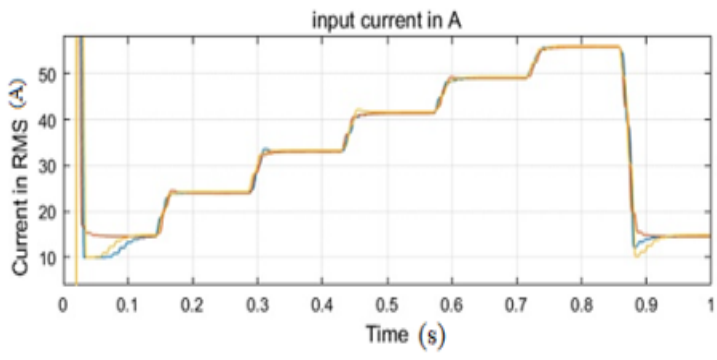

(b)

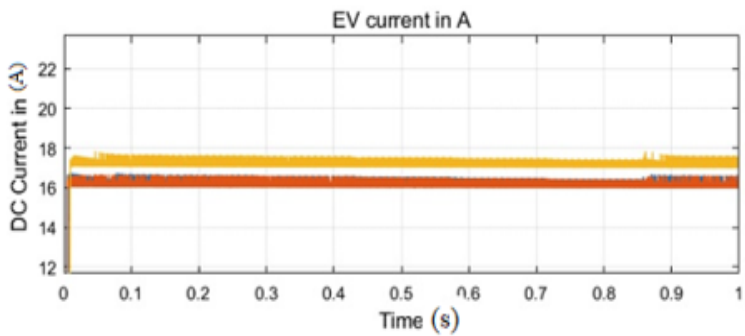

(c)

Figure 5. Case 1: (a) RMS voltage, (b) current of grid and (c) EV current

Table 2. Comparative analysis of scenarios for different cases

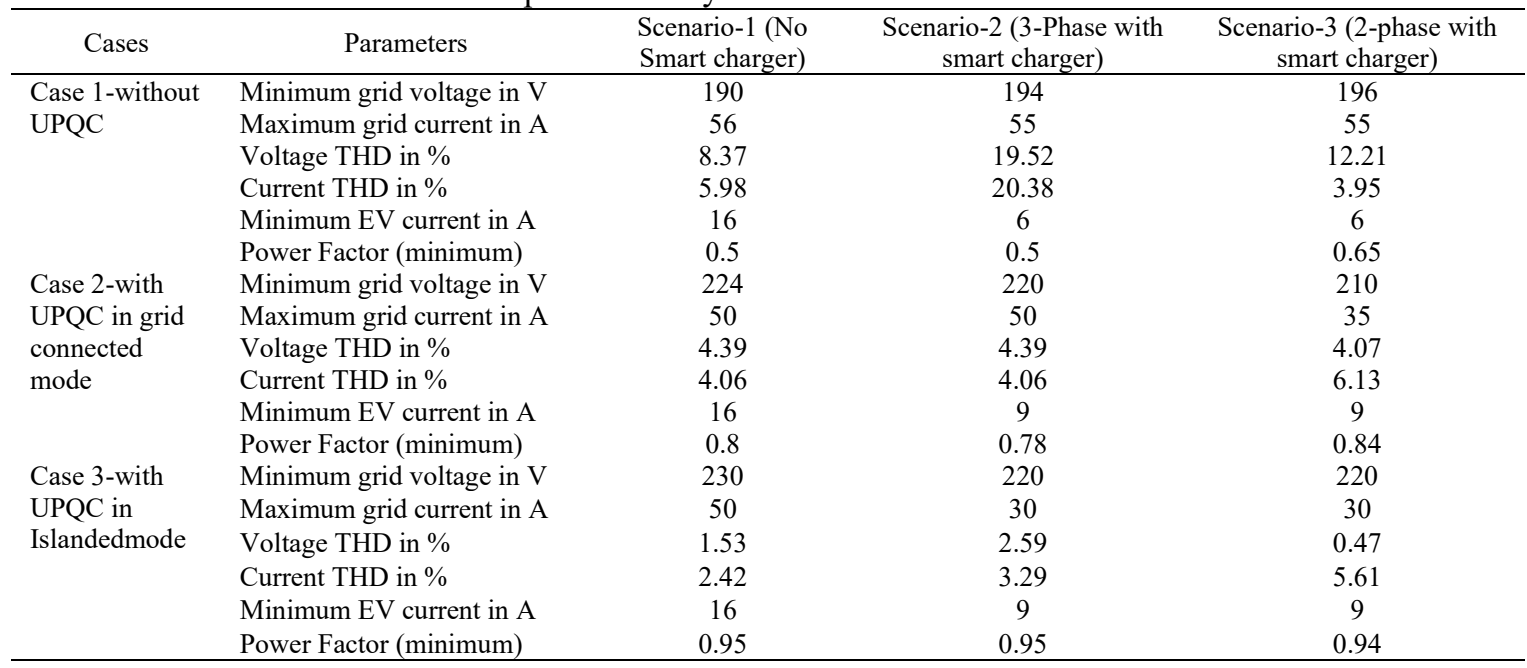

In case 2 the UPQC brought into action to compensate the voltage drop created in the case 1 . This works well with the test system and voltage drop is reduced at the AC grid side which is shown in Figure 6(a) and the grid current is 55A as shown in Figure 6(b). The RMS value of this voltage and current are tabulated in Table 2. Since there is no smart charger action, the EV draws the minimum current of 16A is shown in Figure 6(c).

In case 3 the grid is disconnected and the required power is supplied from the PV based UPQC, which works as the DC to AC inverter to supply the load. In this case also, the voltages are within limit and the maximum grid current is also reduced as shown in Figure 7(a) and 7(b) due to the UPQC.In this case also EV maintains th same grid current of 16A, shown in Figure 7(c). 


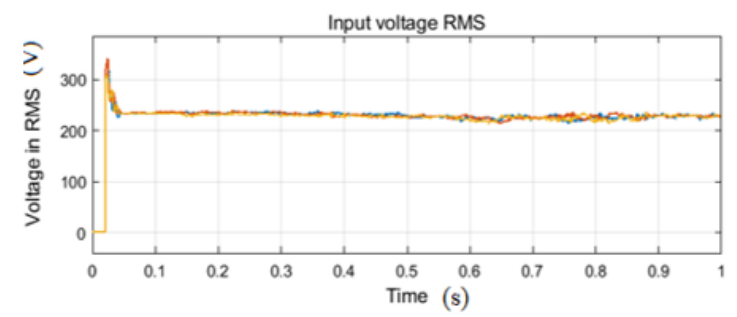

(a)

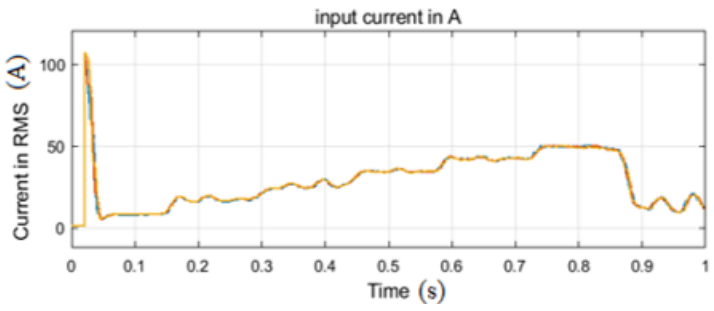

(b)

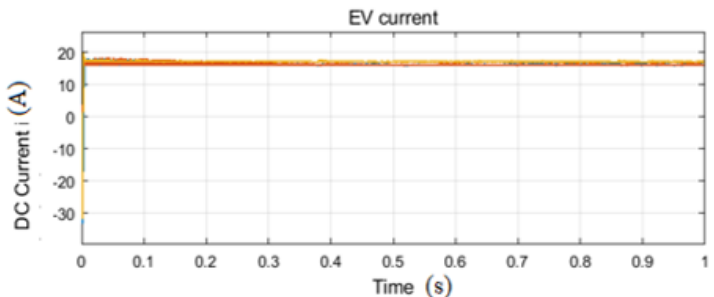

(c)

Figure 6. Case 2: (a) RMS voltage, (b) current of grid and (c) EV current

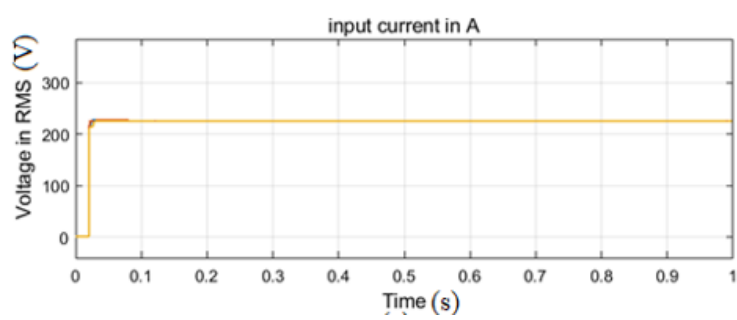

(a)

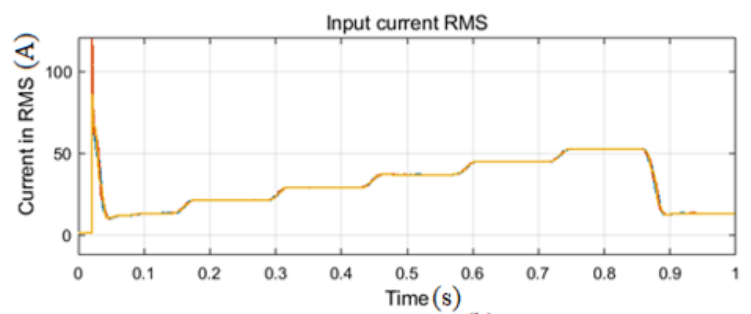

(b)

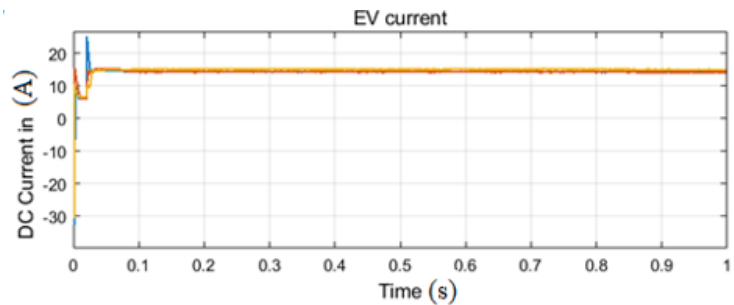

(c)

Figure 7. Case 3: (a) RMS voltage, (b) current of grid and (c) EV current

From this scenario 1 , it is observed that the voltage is within limit when the UPQC is in action. When UPQC is out of service in case 1 the voltages are dropped below $200 \mathrm{~V}$. The values of power factor and Total Harmonic distortion (THD) also within the satisfactory limit when UPQC is in action, the values of power factor and THD of all the three cases in scenario 1 are tabulated in Table 2.

\subsection{Scenario 2: smart charger in $\mathrm{ON}$ state with $6 \mathrm{~A}$ minimum current}

In this scenario both the smart charger and the UPQC brought into action, the grid voltage is now maintained within safer range, the smart charger also not required to reduce the charging current. Here the grid supports dynamic load as well as EV charger due to the connection of UPQC. As the connection of UPQC maintains the voltage, the smart EV charger not required to reduce its current. So, it is beneficial for power quality as well as EVs. In case 3, same operation happens without connection of grid and the PV based DC grid supplies the required AC power through UPQC. There is a small drop in the voltage happens and that is not below 210V. The values of THD and power factor are depicted in Table 2. From this scenario it can be concluded that the voltage sag is compensated, THD is improved and the power factor also in expected limit compared to scenario 1 . 


\subsection{Scenario 3: smart $E V$ charger in action for two phases}

The grid system may work in different load condition with unbalanced load to test the proposed system in unbalanced condition. The scenario 3 works for only two phases, where the dynamic load is connected at B \& C. This creates the unbalancing in the system. In case 1 without connection of UPQC, the voltage drops. In case 2 the UPQC and smart charges are in action. The voltage is balanced and it is within the safer limits. In case 3 the grid is disconnected and the results are similar like scenario2. But the voltages are within safer limits. The PV based DC grid supplies the quality power to the loads. From scenario 3, it is observed that the voltage sag and unbalancing is compensated. THD is improved and the power factor is also in expected limit. These values are tabulated in Table 2.

\section{CONCLUSION}

The AC/DC micro grid is connected with the UPQC and it is tested for three cases and three scenarios. The problems due to the connection of smart charger in the grid supply are solved using the UPQC and the voltage levels are improved. The current harmonics also controlled acceptable limits. The power factor of the system is also improved through this control. These analyses are done for grid connected and islanded mode. In the islanded mode the PV power is supplied to the load via battery. From the results it can be seen that the minimum voltages are below $200 \mathrm{~V}$ in all the scenarios in case 1 (i.e when UPQC is not connected). The case 2 (i.e after connecting the UPQC) gives better voltage stability even when the dynamic load is connected. Then the current taken by the loads from grid also minimum. The THD values also reduced in voltage and the power factor also within acceptable limit. The case 3 is done with islanding mode where grid is not in action, the PV and battery are working together to satisfy the dynamic load as well as the EVs. As UPQC is connected, the voltage of the system is maintained and also harmonics free current is supplied to EV, even though the smart charger is not in action. The smart charger will be in action, when the voltage of grid is reduced drastically. So, the UPQC performs better compared to the EV smart charger in load side as well as source side.

\section{REFERENCES}

[1] S. Paramanik, K. Sarker, D. Chatterjee, and S. K. Goswami, "Smart Grid Power Quality Improvement Using Modified UPQC," 2019 Devices for Integrated Circuit, 2019, pp. 356-360, doi: 10.1109/DEVIC.2019.8783704.

[2] J. Ye, H. B. Gooi, X. Zhang, B. Wang, and U. Manandhar, "Two-Level Algorithm for UPQC Considering Power Electronic Converters and Transformers," 2019 IEEE Applied Power Electronics Conference and Exposition (APEC), 2019, pp. 3461-3467, doi: 10.1109/APEC.2019.8722007.

[3] J. Wang, H. Wu, K. Sun, and L. Zhang, "A High Efficiency Quasi-Single-Stage Unified Power Quality Conditioner Integrating Distributed Generation," 2019 IEEE 10th International Symposium on Power Electronics for Distributed Generation Systems (PEDG), 2019, pp. 1099-1104, doi: 10.1109/PEDG.2019.8807481.

[4] C. K Sundarabalan, Y. Puttagunta, and V. Vignesh, "Fuel cell integrated unified power quality conditioner for voltage and current reparation in four-wire distribution grid," IET Smart Grid, vol. 2, no.1, pp. 60-68, 2019, doi: 10.1049 /iet-stg.2018.0148

[5] S. Devassy and B. Singh, "Design and performance analysis of three-phase solar PV integrated UPQC,"2016 IEEE 6th International Conference on Power Systems (ICPS), 2016, pp. 1-6, doi: 10.1109/ICPES.2016.7584022.

[6] S. Devassy and B. Singh, "Modified pq-Theory-Based Control of Solar-PV-Integrated UPQC-S," in IEEE Trans. Industry Applications, vol. 53, no. 5, pp. 5031-5040, Sept.-Oct. 2017, doi: 10.1109/TIA.2017.2714138.

[7] M. Kurfirt, M. Kaspirek, and J. Hlavnicka, "E-mobility Impact on Supply in Distribution Grid," 2019 20th Int. Scien. Conf. Elec. Pow. Eng., 2019, pp. 1-4, doi: 10.1109/EPE.2019.8778166.

[8] R. Kushwaha and B. Singh, "Power Factor Improvement in Modified Bridgeless Landsman Converter Fed EV Battery Charger," IEEE Trans. Vehic. Tech., vol. 68, no. 4, pp. 3325-3336, 2019, doi: 10.1109/TVT.2019.2897118.

[9] V. A. Katić, A. M, Stanisavljević, B. P. Dumnić, and B. P. Popadić, "Impact of V2G operation of electric vehicle chargers on distribution grid during voltage dips," IEEE EUROCON 2019 -18th International Conference on Smart Technologies, 2019, pp. 1-6, doi: 10.1109/EUROCON.2019.8861904.

[10] P. G. Khorasani, M. Joorabian, and S. G. Seifosadat, "A new proposal for the design of hybrid AC/DC microgrids toward high power quality," Turkish Journal of Electrical Engineering \& Computer Sciences, vol. 25, no. 5, pp. 4033-4049, 2017, doi:10.3906/elk-1609-74.

[11] E. Aprilia, K. Meng, M. Al Hosani, H. H. Zeineldin, and Z. Y. Dong, "Unified Power Flow Algorithm for Standalone AC/DC Hybrid Microgrids," in IEEE Transactions on Smart Grid, vol. 10, no. 1, pp. 639-649, Jan. 2019, doi: 10.1109/TSG.2017.2749435.

[12] F. Li, L. Guo, L. Liu, X. Li, and Q. Wang, "Method to improve charging power quality of electric vehicles," The Journal of Engineering, vol. 2019, no.16, pp 2706-2709, 2019, doi: 10.1049/joe.2018.8544.

[13] S. Martinenas, K. Knezović, and M. Marinelli, "Management of Power Quality Issues in Low Voltage Networks Using Electric Vehicles: Experimental Validation,” in IEEE Transactions on Power Delivery, vol. 32, no. 2, pp. 971-979, April 2017, doi: 10.1109/TPWRD.2016.2614582. 
[14] M. Nassary, M. Orabi, M. Ghoneima, and M. K. El-Nemr, "Single-Phase Isolated Bidirectional AC-DC Battery Charger for Electric Vehicle - Review," 2019 International Conference on Innovative Trends in Computer Engineering (ITCE), 2019, pp. 581-586, doi: 10.1109/ITCE.2019.8646528.

[15] F. Nejabatkhah, Y. W. Li and H. Tian, "Power Quality Control of Smart Hybrid AC/DC Microgrids: An Overview," in IEEE Access, vol. 7, pp. 52295-52318, 2019, doi: 10.1109/ACCESS.2019.2912376.

[16] U. Sharma and B. Singh, "A Generalised Double Integral Sliding Mode Control for Bidirectional Charger of Light Electric Vehicle," 2019 IEEE International Conference on Environment and Electrical Engineering and 2019 IEEE Industrial and Commercial Power Systems Europe, 2019, pp. 1-6, doi: 10.1109/EEEIC.2019.8783407.

[17] A. Verma and B. Singh, "An Implementation of Renewable Energy Based Grid Interactive Charging Station," 2019 IEEE Transportation Electrification Conference and Expo, 2019, pp. 1-6, doi: 10.1109/ITEC.2019.8790455.

[18] D. Wang, J. Liu, L. Piegari, S. Song, X. Chen and D. D. Simone, "A Battery Lifetime Improved Control Strategy of Modular Multilevel Converter for Electric Vehicle Application," 2019 IEEE 10th International Symposium on Power Electronics for Distributed Generation Systems, 2019, pp. 594-598, doi: 10.1109/PEDG.2019.8807628.

[19] L. Zhang, X. Zhang, D. Li and H. Tan, "Research on Power Quality Control Method of V2G System of Electric Vehicle Based on APF," Int. Conf. Adv. Mech. Sys., 2019, pp. 186-189, doi: 10.1109/ICAMechS.2019.8861642.

[20] S. S. Yusuf and N. N. Mustafi, "Design and Simulation of an Optimal Mini-Grid Solar-Diesel Hybrid Power Generation System in a Remote Bangladesh," Int. J. Smart Grids, ijSmartGrid, vol. 2, no. 1, pp. 27-33, 2018.

[21] G. R. Chandra Mouli, J. Schijffelen, M. van den Heuvel, M. Kardolus and P. Bauer, "A 10 kW Solar-Powered Bidirectional EV Charger Compatible with Chademo and COMBO," in IEEE Transactions on Power Electronics, vol. 34, no. 2, pp. 1082-1098, Feb. 2019, doi: 10.1109/TPEL.2018.2829211.

[22] S. Faddel, A. A. S. Mohamed, and O. A Mohammed, "Fuzzy logic-based autonomous controller for electric vehicles charging under different conditions in residential distribution systems," Electric Power Systems Research, vol. 148, pp 48-58, 2017, doi.org/10.1016/j.epsr.2017.03.009.

[23] K. Li, J. Zhang, and J. Zhang, "Research on the Control Strategy of AC/DC Interlinking Converters in Islanded Hybrid Microgrid," IEEE 4th Int. Conf. Elec. Tech., 2021, pp. 479-483, doi: 10.1109/ICET51757.2021.9450958.

[24] O. Azeem et al., "A Comprehensive Review on Integration Challenges, Optimization Techniques and Control Strategies of Hybrid AC/DC Microgrid,” Applied Sciences, vol. 11, no. 14, 2021, doi: 10.3390/app11146242.

[25] J. Jiao, R. Meng, Z. Guan, C. Ren, L. Wang, and B. Zhang, "Grid-connected Control Strategy for Bidirectional ACDC Interlinking Converter in AC-DC Hybrid Microgrid," 2019 IEEE 10th International Symposium on Power Electronics for Distributed Generation Systems (PEDG), 2019, pp. 341-345, doi: 10.1109/PEDG.2019.8807601.

[26] Z. H Saleh, Z. H. Ali, R. W. Daoud, and A. H. Ahmed, "A study of voltage regulation in microgrid using a DSTATCOM," Bulletin of Electrical Engineering and Informatics, vol. 9, no. 5, pp. 1766-1773, 2020, doi: 10.11591/eei. v9i5.2442.

[27] R Aboelsaud, A. Ibrahim, and A. G. Garganeev, "Review of three-phase inverters control for unbalanced load compensation," International Journal of Power Electronics and Drive Systems, vol. 10, no. 1, pp 242-255, 2019, doi: 10.11591/ijpeds.v10.i1.pp242-255.

\section{BIOGRAPHIES OF AUTHORS}
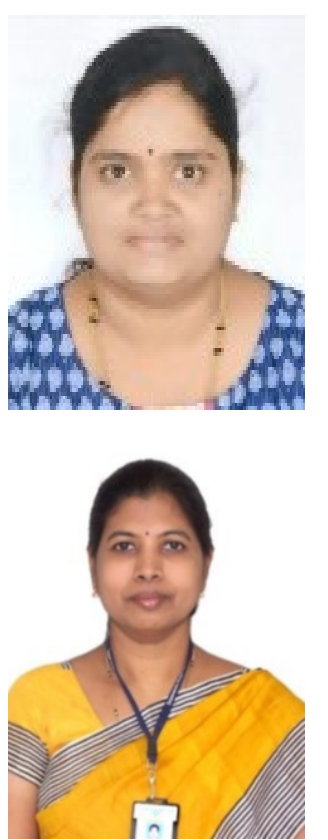

Sumana Sreenivasa Rao is currently working as Assistant professor in the department of Electrical and Electronics Engineering, Dayanandasagar College of Engineering, Bengaluru. She has published papers in national and international conferences. Her area of intrest is Power system, Power quality and Power electriletronics. She is pursuing Ph. D in the area of Power quality.

Dr. Dhanalakshmi Rangaswamy currently working as professor in the department of Electrical and Electronics Engineering at Dayanandasagar College of Engineering, Bengaluru.Her area of interest is Power system, Power electronics and renewable energy sources. She has many publications in reputed journals. 